\title{
Continued efforts to translate diabetes cardiovascular outcome trials into clinical practice
}

\author{
Angelo Avogaro', Gian Paolo Fadini ${ }^{1 *}$, Giorgio Sesti ${ }^{2}$, Enzo Bonora ${ }^{3}$ and Stefano Del Prato ${ }^{4}$
}

\begin{abstract}
Diabetic patients suffer from a high rate of cardiovascular events and such risk increases with HbA1c. However, lowering $\mathrm{HbA1c}$ does not appear to yield the same benefit on macrovascular endpoints, as observed for microvascular endpoints. As the number of glucose-lowering medications increases, clinicians have to consider several open questions in the management of type 2 diabetes, one of which is the cardiovascular risk profile of each regimen. Recent placebo-controlled cardiovascular outcome trials (CVOTs) have responded to some of these questions, but careful interpretation is needed. After general disappointment around CVOTs assessing safety of DPP-4 inhibitors (SAVOR, TECOS, EXAMINE) and the GLP-1 receptor agonist lixisenatide (ELIXA), the EMPA-REG Outcome trial and the LEADER trial have shown superiority of the SGLT2-I empagliflozin and the GLP-1RA liraglutide, respectively, on the 3-point MACE outcome (cardiovascular death, non-fatal myocardial infarction or stroke) and cardiovascular, as well as all-cause mortality. While available mechanistic studies largely support a cardioprotective effect of GLP-1, the ability of SGLT2 inhibitor(s) to prevent cardiovascular death was unexpected and deserves future investigation. We herein review the results of completed CVOTs of glucose-lowering medications and suggest a possible treatment algorithm based on cardiac and renal co-morbidities to translate CVOT findings into clinical practice.
\end{abstract}

Keywords: Cardiovascular outcome trials, Diabetes, Complications, Treatment, Cardiovascular disease

\section{Background}

Type 2 diabetes is characterized by a heavy atherosclerotic burden, inadequate compensatory remodeling and accelerated plaque progression, despite extensive use of medical therapies [1]. In diabetic patients, macrovascular and microvascular disease are tightly linked: patients with proliferative retinopathy have a 25 -fold higher risk for lower limb amputation and a 2-3 fold higher risk for coronary heart disease (CHD) as compared to those without [2]. These features account for an increased cardiovascular disease (CVD) morbidity and mortality. CVD may be present at $\mathrm{HbAlc}$ values below the diagnostic threshold for diabetes [3], and in patients with overt type 2 diabetes, for every percentage point increase in HbA1c,

\footnotetext{
*Correspondence: gianpaolofadini@hotmail.com

1 Department of Medicine, University of Padova, Via Giustiniani 2,

35128 Padova, Italy

Full list of author information is available at the end of the article
}

the relative risk of CVD increases by about $18 \%$ [4]. For these reasons, the latest ESC/EASD Guidelines on diabetes, pre-diabetes, and CVD emphasize the need for a stringent approach in patients with diabetes, underlying the importance of a patient-centered care [5]. In summary, in patients with type 2 diabetes, there is an excess risk and burden of CVD, which parallels the worsening of glycemic control.

Several mechanisms are though to be responsible for cardiovascular damage in diabetic patients, including hyperglycemia and oxidative stress [6], hypoglycemia [7], hyperinsulinemia and insulin resistance $[8,9]$. These mechanisms can be countered by the use of different glucose-lowering medications, which are therefore expected to reduce cardiovascular risk in patients with diabetes, in addition to lowering HbA1c $<7.0 \%$, which is still considered the goal to maximise cardiovascular benefit $[10,11]$. Nonetheless, a survey from the ESC suggests that there is 
wide space to improve the management of patients with diabetes and cardiovascular disease [12].

We herein aim to briefly re-analyse the results of randomized controlled trials (RCTs) reporting the effects of various glucose-lowering medications on cardiovascular outcomes in patients with type 2 diabetes. To this end, we run a PubMed search for RCTs with the following terms: "type 2 diabetes" "randomized controlled trial" "cardiovascular" and screened for cardiovascular outcome trials (CVOTs) assessing safety or efficacy of glucose-lowering medications.

\section{The macrovascular paradox}

While there is much evidence that the risk of CVD increases along with $\mathrm{HbA1c}$, intervention trials aimed at determining whether tight glycemic control is associated with a reduction in CVD have offered controversial results (meta-analyzed in [13]). This is reflected, for example, by the observation that there is no correlation between the glycaemic control and coronary vascular function in diabetic patients [14]. We call this the "macrovascular paradox": i.e. the failure to reduce macrovascular complications to the same extent as the microvascular complications, despite comparable reductions in HbA1c. A number of algorithms have been proposed to ensure glycemic control whenever lifestyle measurements fail to keep HbA1c at target. The choice of drugs in the treatment strategy is mainly based on efficacy, risk of hypoglycaemia, effect on body weight, other side effects and, ultimately, costs. Effect on CVD risk is an important item that may guide drug selection. Multiple reasons have been claimed to potentially account for the negative findings of CVD reduction trials, including: drug-induced hypoglycemia, weight gain, other side effects, wrong HbA1c target, short duration of the trials. A likely explanation for the CVD paradox may rely on the multifactorial nature of the CVD risk in diabetes, as highlighted by the results of the STENO-2 study [15]. As a corollary of this, pharmacologic agents with effects exceeding the glucose lowering action may be expected to confer either negative or positive impacts on CVD.

\section{Trials on cardiovascular effects of glucose lowering agents}

Several articles have already extensively reviewed preclinical and clinical findings on the cardiovascular effects of glucose-lowering medications [16-21]. We herein focus on data coming from early trials and from so-called cardiovascular outcome trials (CVOT) requested by regulatory agencies for marketing authorization approval [22].

Metformin is widely accepted as the first-choice agent for glucose lowering largely because of the results of the
UKPDS sub-study showing a significant $39 \%$ reduction in myocardial infarction (MI) in a limited number of overweight diabetic patients. After 10 years of the UKPDS post-trial monitoring, a significant reduction in nonfatal MI was observed in patients in the intensive arm (initially treated with insulin or sulfonylureas) [23]. However, metformin use has been recently questioned on the basis of both efficacy and outcomes [24]. In the UKPDS, the SU use, despite significant increase in hypoglycemia, was not associated to an increase in MI fatality compared to no SU use [25]. The action in diabetes and vascular disease: preterax and diamicron modified release controlled evaluation (ADVANCE) trial showed that intensive glycemic control based on gliclazide modified release reduced the incidence of combined major macro- and microvascular events, primarily because of a reduction in the incidence of new or worsening nephropathy [26]. In the Outcome Reduction With an initial glargine intervention (ORIGIN) trial, early use of basal insulin to achieve normal fasting plasma glucose levels had no effect on CVD outcomes compared with guideline-suggested glycemic control [27].

In the STOP-NIDDM trial, acarbose was initially suggested to reduce cardiovascular risk in patients with impaired glucose tolerance [28]. Furthermore, a metaanalysis of long term studies concluded that a similar effect may be present in type 2 diabetes, but the number of patients was very small and the conclusion of the analysis was very controversial and not reproducible [29-31].

An additional option in treatment algorithms is the use of thiazolidinediones. In the Prospective Pioglitazone Clinical Trial in Macrovascular Events (PROactive), pioglitazone, a PPAR-gamma agonist, when added to baseline anti-hyperglycemic regimen, had no apparent benefit on a broad, combined, primary end point [32]. However, a pre-specified secondary outcome (MI, stroke, and cardiovascular mortality) was reduced by $16 \%$, in spite of an increase in heart failure (HF). A different tale is known for rosiglitazone, which has been implicated in an increase risk of MI [33, 34], although most recent analyses have casted doubts on the initial data interpretation [35]. Negative CVD outcomes have been reported with the use of dual PPAR alpha-gamma agonists Tesaglitazar and Muraglitazar [36].

\section{The lesson of the cardiovascular outcome trials}

In 2008, following the withdrawal of rosiglitazone from the market because of potential negative impact on CVD outcomes [33, 34], the Food and Drug Administration (FDA) issued guidance on the assessment of CVD risk for all new drugs to treat type 2 diabetes [22]. Following this, a large number of patients with type 2 diabetes have been enrolled in CV outcome trials (CVOT, summarized 
in Table 1). We now have the results of 6 of such trials: 3 assessing safety of dipeptidyl peptidase (DPP) 4 inhibitors [37-39], 2 testing the safety of a glucagon-like peptide-1 receptor agonist (GLP1-RA) [40, 41], and 1 of an inhibitor of the sodium-glucose co-transporter (SGLT)-2 [42]. All DPP4-I CVOTs met the safety primary endpoint of non-inferiority versus placebo with respect to 3-point MACE (CVD mortality, non-fatal myocardial infarction, and non-fatal stroke). In the Saxagliptin Assessment of Vascular Outcomes Recorded in Patients with Diabetes Mellitus (SAVOR) trial, a statistically significant increase in hospitalization for HF was observed in the patients randomized to saxagliptin, although no increase in CVD mortality occurred in these individuals. This was not observed in CVOTs assessing sitagliptin and alogliptin $[38,39]$. The issue of hospitalization for heart failure has been subsequently analyzed in several observational trials [43] and meta-analyes [44], most concluding for a neutral effect of DPP4-I on heart failure risk.

In the evaluation of lixisenatide in acute coronary syndromes (ELIXA) trial, the use of lixisenatide in diabetic patients with a recent acute coronary syndrome showed neutrality on CVD outcomes with no increase in the risk of heart failure hospitalization [40].

Both DPP4-I and GLP-1RA have been integrated in treatment algorithms before the results of these trials were published/disclosed, mainly because of the favorable efficacy-safety profile. With the question remaining open with respect to the increased risk of hospitalization for heart failure reported in SAVOR trial (not confirmed in any other study), overall evidence is available for safe use of DPP4-I across populations with different degree of CVD risk, including those with recent acute coronary syndrome [38]. Though these results have been welcome as reassuring, the diabetes community continues asking whether these treatments may, under different circumstances, lend to some degree of CVD protection.

\section{EMPA-REG Outcome trial and LEADER trial}

Results of the two latest CVOTs, namely the EMPA-REG Outcome trial [42] and the Liraglutide effect and action in diabetes: Evaluation of cardiovascular outcome results (LEADER) trial [41] have recently stirred much enthusiasm. In these trials, as in SAVOR, TECOS and ELIXA, diabetic patients at very high CVD risk, were enrolled to determine the CVD safety of the SGLT2 inhibitor empagliflozin and the GLP-1RA liraglutide.

In the EMPA-REG Outcome trial, the primary outcome was a composite of death from CV causes, nonfatal myocardial infarction, and nonfatal stroke (3-point MACE). Two daily doses of the drug were tested: 10 and $25 \mathrm{mg}$. As compared to placebo, empagliflozin (pooled analyses of 10 and $25 \mathrm{mg}$ ) showed non-inferiority for 3-point MACE, non-inferiority for 4-point MACE (including hospitalization for unstable angina), superiority for 3-point MACE and not for 4-point MACE. With respect to secondary endpoints, patients randomized to empagliflozin had significantly reduced risk of hospitalization for HF by $35 \%$, reduced risk CV death by $38 \%$, and reduced risk for allcause mortality by $32 \%$. The mechanisms responsible for these results are still unclear, being possibly related to pleiotropic effects on risk factors, to hemodynamic effects, and possible direct effects on the heart and vasculature $[45,46]$. Furthermore, empagliflozin, compared to placebo, significantly slowed progression of kidney disease and loss of glomerular filtration over time in highrisk patients of the EMPA-REG Outcome trial [47].

In the LEADER trial, the primary endpoint was the same as in the EMPA-REG Outcome trial [41]. In the primary data set and in per protocol analyses, compared to placebo, liraglutide significantly reduced occurrence of the 3-point MACE by $13 \%$, cardiovascular death by $22 \%$, and all-cause mortality by $15 \%$, without significant effects on non-fatal MI, non-fatal stroke and hospitalization for heart failure [41]. These findings appear to some extent similar to what observed in the EMPA-REG Outcome trial, and occurred in parallel with mild reductions in body weight and systolic blood pressure [41].

In EMPA-REG, the early and unusual divarication of mortality curves deserves attention. Unlike in the LEADER, such a rapid effect suggests treatment has little effect on the atherosclerotic process pointing for an effect unlikely to be mediated through the modulation of glucose or lipid metabolism. Similarly, the modest reduction of body weight, is unlikely to account for the reported effect. More interesting is the effect on blood pressure, although prior trials using blood pressure lowering drugs have shown a positive effect on CVD outcome to occur at a later time than in EMPA-REG [48]. A minor impact on the atherosclerotic process is also supported by the lack of any significant effect on nonfatal MI and stroke. These results suggest that the use of empagliflozin does not necessary protect from the $\mathrm{CV}$ event, rather with the mortality linked to the event itself.

Of note, the early separation of the mortality curves is paralleled by an even earlier divarication of the curves for hospitalization for heart failure, suggesting at least part of the beneficial effect of empagliflozin to be exerted through volume depletion: in keeping with this, a $4 \%$ hematocrit increase was recorded in the empagliflozin treated patients [49]. Ferrannini et al. have speculated on the mechanisms at work suggesting that a switch to fatty acid utilization, concurrent with better oxygen delivery to the tissues, cooperates with small changes in body weight and blood pressure to achieve cardioprotection by SGLT2 inhibition [50]. 


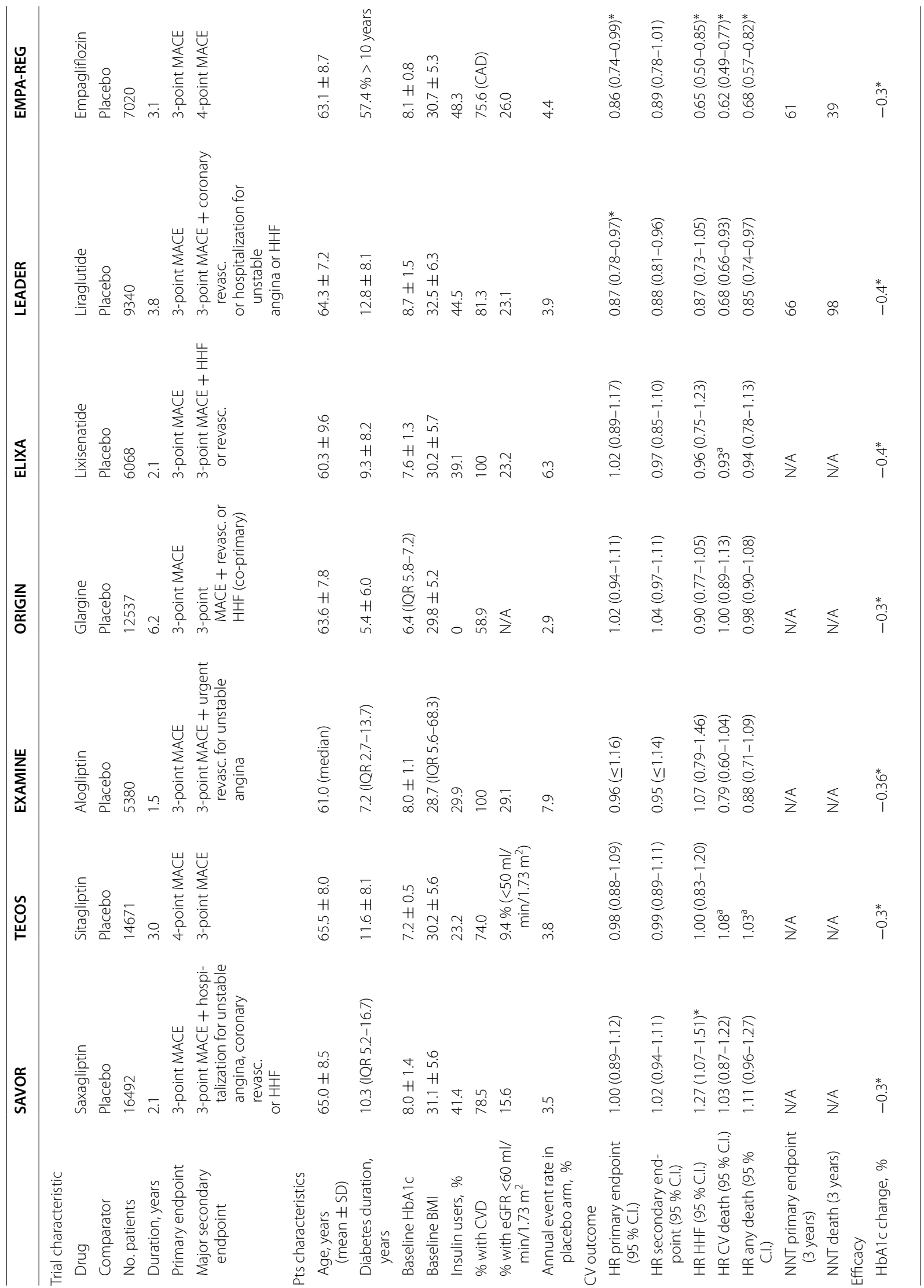




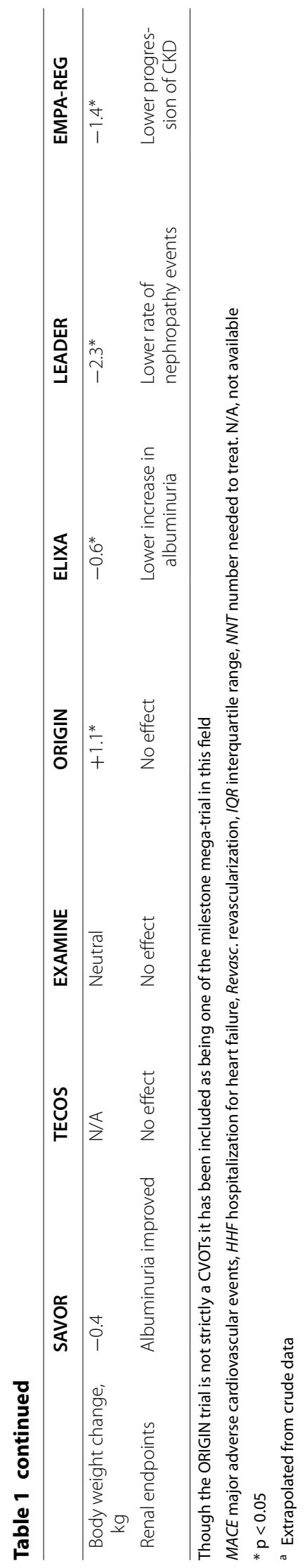


In the LEADER trial, survival curves for 3-point MACE and mortality separate later (since about $12-18$ months from randomization), and there were no effect on heart failure. This observation suggests that liraglutide, differently from empagliflozin, may reduce the occurrence of cardiovascular events mainly by preventing progression of atherosclerosis, possibly thanks to a better control of risk factors and despite a mild rise in heart rate [41]. This view is supported by a wealth of pre-clinical and pathophysiologic studies (reviewed in [17]).

While we wait for additional studies able to clarify which mechanism(s) can explain the improvement in CVD outcomes by empagliflozin and liraglutide, the clinical implications of these results need to be critically put in the perspective of current guidelines, treatment algorithms, and health care economy. With respect to this, a number of questions need to be addressed: 1 . Can the results obtained with empagliflozin and liraglutide extended to other drugs of the same class? By now, of the two GLP-1RA evaluated in CVOTs, only liraglutide, but not lixisenatide, achieved cardioprotection. Before concluding for a drug-specific effect, differences in the patient populations and study design between ELIXA and LEADER trials should be taken into account (Table 1), whereas results of ongoing trials with other GLP-1RAs will help concluding on a class-effect. 2. As the proportion of patients with established CVD was high in the EMPAREG (75.6 \% had CAD) and LEADER (81.3 \% had CVD), can the results obtained be translated to other patient categories, i.e. patients without established CVD? 3. Is there a specific sub-population that may derive a specific benefit from the treatment with SGLT2-I and GLP-RA? Answering these questions will require further analysis of the EMPA-REG and LEADER databases as well as more specific clinical and mechanistic studies. So far, in both the EMPA-REG Outcome trial and the LEADER trial, there is a signal indicating that patients with renal impairment are those who benefited most from treatment with empagliflozin and liraglutide, respectively, as both drugs appear to reduce kidney-related endpoints [41, 47]. Yet, initiating therapy with empagliflozin is still not recommended in patients with eGFR $<60 \mathrm{ml} / \mathrm{min} / 1.73 \mathrm{~m}^{2}$. While this limitation may change in the near future, liraglutide can already be used in patients with stage III CKD, being not indicated in patients with eGFR $<30 \mathrm{ml} / \mathrm{min} / 1.73 \mathrm{~m}^{2}$.

Results of the CVOT with canagliflozin (CANVAS) and dapagliflozin (DECLARE) will shed further light on the results obtained with empagliflozin, possibly showing whether the beneficial effects shown in the EMPA-REG outcome trial can be extended to the SGLT2-inhibitor class and to individuals with a different $\mathrm{CV}$ risk profile [21].

Yet, a 22 and $38 \%$ risk reduction of CVD mortality observed with liraglutide and empagliflozin, respectively, is too strong to be overlooked, and will likely require a favorable revision of the positioning of these drugs in the current treatment algorithm of type 2 diabetes. In order to do so, some features of the EMPA-REG and LEADER trials are worth a consideration. First of all, the results of the trial pertain to a well-defined diabetic population, i.e. patients with established prior CV events. As such, it cannot be generalized to the wide spectrum of clinical diabetes; in this context, particularly striking have been the superiority of the primary outcome in patients with an age $\geq 65$ years, and the death for $\mathrm{CV}$ causes in the group with body mass index $<30 \mathrm{~kg} / \mathrm{m}^{2}$.

\section{Comorbidities-driven treatment}

In patients with type 2 diabetes, especially in the elderly, the presence of CVD is central, with emphasis on concomitant heart failure and chronic kidney disease (CKD). In obese patients, treatment should aim at improving glycemic control and reducing body weight. Although evidence for the $\mathrm{CV}$ protection of metformin is rather limited, the drug has become quite familiar after more than 50 years of use, has advantageous cost effectiveness and a modest lowering effect on body weigh to remains the preferred background treatment.

If the patient has asymptomatic CVD or prior MACE and eGFR $\geq 60 \mathrm{ml} / \mathrm{min} / 1.73 \mathrm{~m}^{2}$ and heart failure NYHA class I-III, metformin plus empagliflozin/liraglutide should be considered as these are the typical patients included in the EMPA-REG Outcome and LEADER trials, with liraglutide currently being usable in stage III CKD. For patients with no sign of heart failure, either pioglitazone (or DPP4-I) may represent a therapeutic option. For patients with a eGFR of $60-30 \mathrm{ml} /$ $\mathrm{min} / 1.73 \mathrm{~m}^{2}$, liraglutide should be consider the preferred choice. Though $26 \%$ of patients in the EMPA-REG Outcome trial fell in this eGFR category and they benefited most in terms of cardiovascular protection, initiation of empagliflozin is currently discouraged in stage III CKD, and lower glycemic effect is expected. DPP4-I can be used even with an eGFR $<30 \mathrm{ml} / \mathrm{min} / 1.73 \mathrm{~m}^{2}$ because of their overall safety and efficacy, granted dose adjustment is made for the compounds requiring it.

If the patient has evidence of CKD without heart failure, pioglitazone can be a reasonable option as shown in a subanalysis of the PROactve trial [51]. Insulin and SU, if needed, should be used with caution because of potential risk of hypoglycaemia, for the latter gliclazide modified release may be a preferred choice because of the available data obtained in ADVANCE [26]. The ORIGIN trial has clearly demonstrated cardiovascular safety of insulin glargine, and the risk of hypoglycemia with basal insulin is lower than during basal-bolus regimen. However, as glargine and liraglutide show similar glycemic effects $[52,53]$, 
the latter should be preferred for the lower hypoglycemia risk [54] and in view of the LEADER trial [41], except for eGFR $<30 \mathrm{ml} / \mathrm{min} / 1.73 \mathrm{~m}^{2}$. In general terms, use of insulin has been shown to be effective even in the log run in patients with acute coronary syndrome in the DIGAMI 1 trial $[55,56]$, though superiority of insulin over standard care was not confirmed the DIGAMI 2 [57].

In patients without CVD, a SGLT2-I or a GLP-1RA should be considered if body weight loss is required, whereas a DPP4-I can be considered whether when weight neutrality is sought. In this context, incretinbased therapy has greater $\mathrm{HbA} 1 \mathrm{c}$ reduction if patients have obesity/metabolic syndrome with a greater effect for GLP-1RA as compared to DPP4-I [58]. Pioglitazone could be considered if obesity is associated with evidence for marked insulin resistance as supported by the co-existence of dyslipidemia, inflammatory markers, and subclinical CVD [59, 60].

In non-obese or mildly obese patients, the prevention of body weight gain may represent an important target along with glycemic control. In this case, a DPP4-I can represent a good choice due to its weight neutrality and the overall and CVD safety. In the case of leaner patients, additional treatment options may be gliclazide modified release and insulin. The former has been shown to significantly decrease new or worsening nephropathy with relatively little risk for severe hypoglycemia [26], while CV safety of basal insulin in the early stage of diabetes is supported by the results of the ORIGIN study [27]. It must be mentioned that in many patients, triple (if not quadruple) oral or oral plus injective treatment becomes necessary during the course of the disease: this implies subsequent decisions about drug combinations. Nowadays choices are multiple and it should always be carefully considered the many aspects of clinics phenotype as suggested by the ADA/EASD guidelines. This makes the proposition of a more stringent algorithm difficult (Fig. 1).

\section{Limitations}

The view presented in this article is largely based on results from RCTs. It should be noted that, although such mega-trials provide the highest level of evidence, they have intrinsic characteristics that limit their

\begin{tabular}{|c|c|c|c|c|}
\hline $\int_{-1} \underbrace{5}_{\rightarrow}$ & $\begin{array}{c}\text { Normal or } \\
\text { subclinical } \\
\text { ENDOTHELIAL } \\
\text { DYSFUNCTION }\end{array}$ & $\begin{array}{c}\text { ESTABLISHED } \\
\text { ATHERO- } \\
\text { SCLEROSIS }\end{array}$ & $\begin{array}{c}\text { ACUTE } \\
\text { CORONARY } \\
\text { SYNDROME }\end{array}$ & $\begin{array}{c}\text { HEART } \\
\text { FAILURE }\end{array}$ \\
\hline $\begin{array}{l}\text { Stage I-II CKD } \\
\text { eGFR } 90-60 \\
\mathrm{ml} / \mathrm{min} / 1.73 \mathrm{~m}^{2}\end{array}$ & $\begin{array}{l}\text { Metformina, } \\
\text { Pioglitazone } \\
\text { DPP4-|ce- , GLP-1 } \\
\text { RA', SGLT2-I9, } \\
\text { Insulin'h SUs }\end{array}$ & \begin{tabular}{|} 
Metformin, SGLT2-Is, \\
GLP-1RA \\
Pioglitazone \\
|c- DPP4-, Insulin', \\
Gliclazide $^{\mathrm{k}}$
\end{tabular} & $\begin{array}{l}\text { Insulinm } \\
\text { DPP4-Ie, } \\
\text { GLP-1RAi, }\end{array}$ & $\begin{array}{l}\text { SLGT2-|l9 } \\
\text { DPP4-|d,e, } \\
\text { GLP-1RA', } \\
\text { Insulin }\end{array}$ \\
\hline $\begin{array}{l}\text { Stage III CKD } \\
\text { eGFR } 59-30 \\
\mathrm{ml} / \mathrm{min} / 1.73 \mathrm{~m}^{2}\end{array}$ & $\begin{array}{c}\text { Metformin }^{2} \\
\text { Pioglitazone } \\
\text { SLGT2-149, GLP- } \\
\text { 1RA', DPP4-|2c-e, } \\
\text { Gliclazide' }^{2 k} \text {, Insulin }\end{array}$ & $\begin{array}{c}\text { Metformin }{ }^{2}, \text { GLP- } \\
\text { 1RA', SGLT2-|49, } \\
\text { Pioglitazone } \\
\text { DPP4-|l2-e, Insulin } \\
\text { Gliclazide } \\
\text { Gk }\end{array}$ & $\begin{array}{l}\text { Insulinm } \\
\text { DPP4-Ie, } \\
\text { GLP-1RAi, }\end{array}$ & $\begin{array}{l}\text { SLGT2-Ig } \\
\text { DPP4-|d,e, } \\
\text { GLP-1RA', } \\
\text { Insulin }\end{array}$ \\
\hline $\begin{array}{l}\text { Stage IV CKD } \\
\text { eGFR } 29-15 \\
\mathrm{ml} / \mathrm{min} / 1.73 \mathrm{~m}^{2}\end{array}$ & $\begin{array}{l}\text { Pioglitazone }^{3} \\
\text { DPP4-I', } \\
\text { Insulin² }\end{array}$ & $\begin{array}{l}\text { Pioglitazone }^{3} \text {, } \\
\text { DPP4-I', } \\
\text { Insulin² }\end{array}$ & $\begin{array}{l}\text { DPP4-I' } \\
\text { Insulin² }\end{array}$ & $\begin{array}{l}\text { DPP4-I' } \\
\text { Insulin² }\end{array}$ \\
\hline $\begin{array}{c}\text { Stage V CKD } \\
\text { eGFR }<15 \\
\mathrm{ml} / \mathrm{min} / 1.73 \mathrm{~m}^{2}\end{array}$ & $\begin{array}{l}\text { Pioglitazone }^{3}, \\
\text { DPP4-I', } \\
\text { Insulin }\end{array}$ & $\begin{array}{l}\text { Pioglitazone }^{3} \text {, } \\
\text { DPP4-I', } \\
\text { Insulin² }\end{array}$ & $\begin{array}{l}\text { DPP4-I², } \\
\text { Insulin² }\end{array}$ & $\begin{array}{l}\text { DPP4-I'2, } \\
\text { Insulin }^{2}\end{array}$ \\
\hline
\end{tabular}

Fig. 1 A treatment algorithm based on cardiac and renal co-morbidities and CVOTs. ${ }^{1}$ To be used with caution because of the risk of hypoglycemia; ${ }^{2}$ consider dose reduction (except for linagliptin) and monitor eGFR frequently; ${ }^{3}$ preferred in the presence of marked insulin resistance; ${ }^{4}$ initiation of

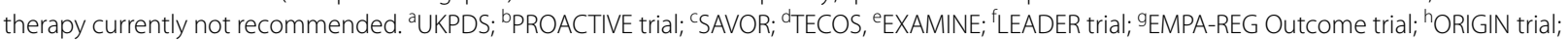
${ }^{k} A D V A N C E ;$ jELIXA; mDIGAMI 1 
generalizability and transferability to clinical practice. We have already mentioned that the study population in most CVOTs is very different from the entire population of patients who are entitled to receive the respective medication. In fact, RCTs differ from clinical practice in several instances. For this reason, there is great interest in real world evidence (RWE) on glucose-lowering medications and how these fit with results from RCTs (Fig. 2). Data from RWE studies can complement RCTs, but they provide a lower level of evidence and can yield quite different results. This has been clearly shown for the risk of hospitalization for heart failure in DPP-4i treated patients, where meta-analyses of RCTs and observational studies [43] can reach to different conclusions [44]. Nonetheless, we endorse the importance of RWE in the evaluation of glucose-lowering medications, especially to explore aspects that cannot be extracted from RCTs. For instance, placebo-controlled RCTs may be poorly informative for clinical practice because they do not provide a comparative assessment of different glucose-lowering medications against cardiovascular outcomes, whereas RWE data can evaluate complex regimens against cardiovascular risk [61].

In addition, we would like to underline that the pharmaco-centric view presented here ignores the importance of a healthy lifestyle and a comprehensive approach to prevent cardiovascular disease, as originally shown in the STENO-2 study [15], and confirmed by the analysis of treatment-dependent and -independent factors associated with cardiovascular morbidity [62], as well as by the effects of a multidisciplinary risk assessment and management program [63]. Although the Look-AHEAD study found no cardiovascular benefit of an intensive lifestyle intervention that promoted weight loss [64], there are still reasons to recommend lifestyle changes in type 2 diabetes mellitus and obesity since early disease stages [65]. Finally, bariatric surgery, another non-pharmacologic approach, may reduce cardiovascular risk in obese people with type 2 diabetes, as shown by recent metaanalyses of observational studies $[66,67]$.

\section{Conclusions}

The most recent CVOTs have expanded our knowledge on the potential effects of glucose-lowering agents on CVD risk. Though most of them have proven CVD safety, the EMPA-REG Outcome trial and LEADER trial have provided evidence for significant improvement of CVD outcomes. While we do not yet have firm explanations for the mechanisms accounting for the observed beneficial effect or whether any specific population may benefit more (for instance patients with heart failure or CKD), it sounds legitimate to try putting these observations in the

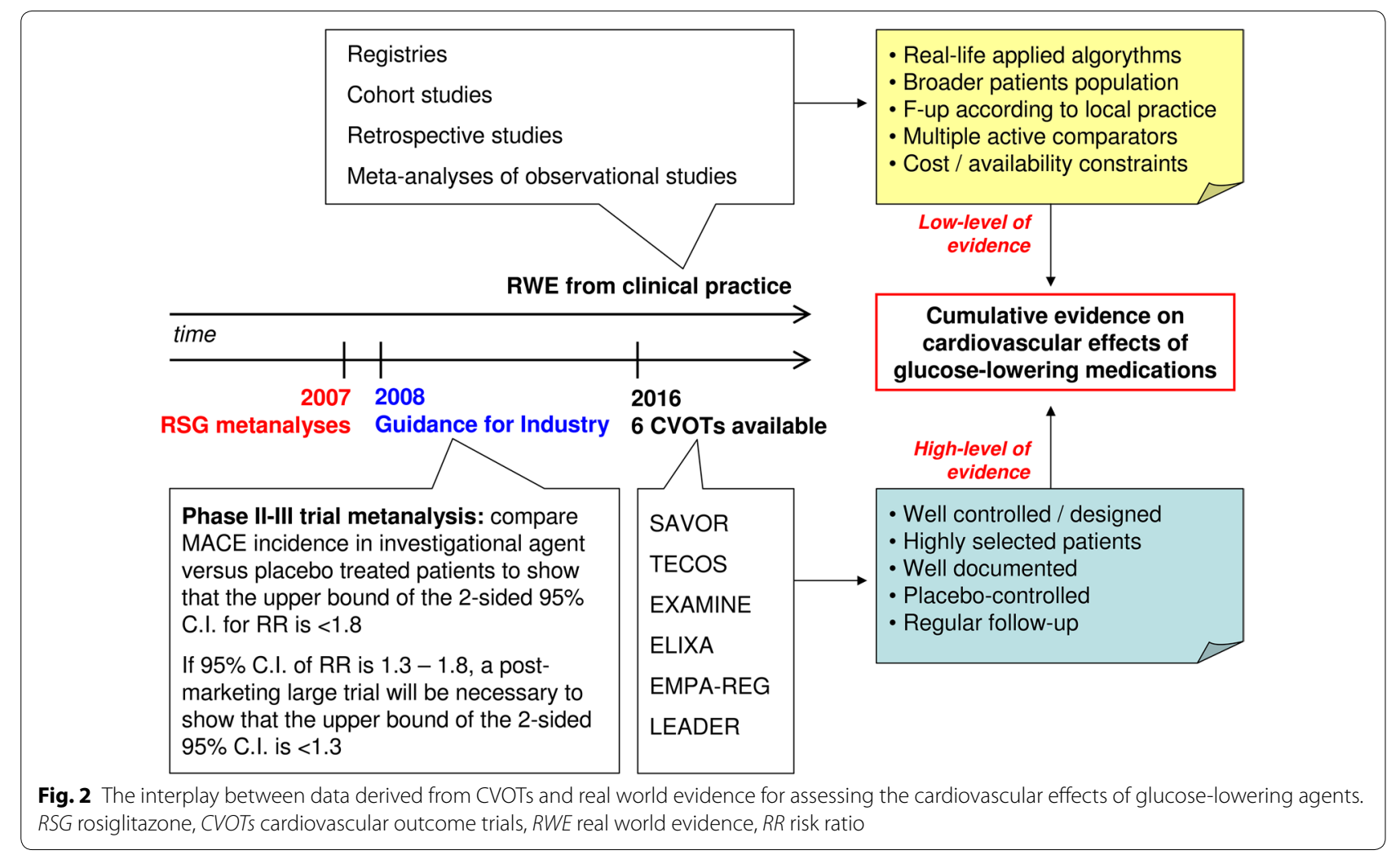


perspective of current treatment algorithms. We believe this exercise is needed to avoid inappropriate over-use of SGLT2-I and GLP-1RA, before all needed information is gathered while ensuring they are used in keeping with the available evidence. Central to our proposal is the presence of CVD. Patient's phenotype, degree of renal function, presence of heart failure, allows for a further patient's population breakdown for more appropriate pharmacologic treatment selection. The results of the EMPA-REG and LEADER trials mostly support the use of empagliflozin or liraglutide in patients who have established CVD, a prior MACE, with or without stage I-III CKD, but we still do not know whether similar positive effects should be extended to the other drugs of the same classes.

The prevention of CVD complications and the safe treatment of patients who already have suffered a CVD event, especially in the elderly patients, remain a major task in treating type 2 diabetes. CVOTs and RWE data represent the basis for evidence-based treatment though we must acknowledge this is a moving target as results of new and ongoing trial will be released requiring a constant revision of treatment algorithms.

\begin{abstract}
Abbreviations
ADA: American Diabetes Association; ADVANCE: action in diabetes and vascular disease: preterax and diamicron modified release controlled evaluation; CAD: coronary artery disease; CHD: coronary heart disease; CKD: chronic kidney disease; CVD: cardiovascular disease; CVOT: cardiovascular outcome trial; DIGAMI: diabetes and insulin-glucose infusion in acute myocardial infarction; DPP4: dipeptydil peptidase 4; EASD: European Association for the Study of Diabetes; eGFR: estimated glomerular filtration rate; ELIXA: evaluation of lixisenatide in acute coronary syndromes; EMPA-REG: empagliflozin cardiovascular outcome event trial in type 2 diabetes mellitus patients; ESC: European Society of Cardiology; GLP-1: glucagon-like peptide 1; HF: heart failure; LEADER: liraglutide effect and action in diabetes: evaluation of cardiovascular outcome results; MACE: major adverse cardiovascular events; MI: myocardial infarction; NYHA: New York Heart Association; ORIGIN: outcome reduction with an initial glargine intervention; PPAR: peroxisome proliferator activating receptor; PROactive: prospective pioglitazone clinical trial in macrovascular events; RCT: randomized clinical trial; RWE: real world evidence; SAVOR: the saxagliptin assessment of vascular outcomes recorded in patients with diabetes mellitus; SGLT2: sodium-glucose cotransporter 2; STOP-NIDDM: stop non insulin dependent diabetes mellitus; SU: sulphonylurea; TECOS: Sitagliptin Cardiovascular Outcomes Study; UKPDS: United Kingdom Perspective Diabetes Study.
\end{abstract}

\section{Authors' contributions}

All authors contributed substantially to study conception and design, acquisition of data, or analysis and interpretation of data, drafting the article or revising it critically. All authors read and approved the final manuscript.

\section{Authors' information}

Authors are officers of the Italian Society of Diabetology, but the views presented in this article are not necessarily those of the Society's position on diabetes pharmacotherapy.

\section{Author details}

${ }^{1}$ Department of Medicine, University of Padova, Via Giustiniani 2, 35128 Padova, Italy. ${ }^{2}$ Department of Medical and Surgical Sciences, University Magna Graecia of Catanzaro, Catanzaro, Italy. ${ }^{3}$ Department of Medicine, Division of Endocrinology, Diabetes and Metabolism, UOC Endocrinologia,
University Hospital of Verona, Verona, Italy. ${ }^{4}$ Section of Metabolic Diseases and Diabetes, Department of Clinical and Experimental Medicine, University of Pisa, Via Paradisa, 2, 56124 Pisa, Italy.

\section{Acknowledgements \\ None.}

\section{Competing interests}

A.A. received funding or lecture fees from the following pharmaceutical industries: Merck Sharp \& Dome, Astrazeneca, Novartis, Boeringher Ingelheim, Sanofi, Mediolanum, Janssen, Novo-Nordisk, Lilly, Servier, and Takeda. GPF received funding or lecture fees from the following pharmaceutical industries: Merck Sharp \& Dome, Astrazeneca, Novartis, Boeringher Ingelheim, Sanofi, Novo-Nordisk, Lilly, Servier. GS received fees for consultancy from Servier, Intarcia, Novo Nordisk, Janssen, Boehringer Ingelheim, Eli Lilly, Astra Zeneca, MSD Italy, and speaker's fees from Novo Nordisk, MSD Italy, Boehringer Ingelheim, Eli Lilly, Sanofi, Janssen, Astra Zeneca, and Takeda. EB in the last five years received honoraria for consulting activity and/or speaking engagement and/ or research support from Abbott, AstraZeneca, Boehringer Ingelheim, Bruno Farmaceutici, Eli Lilly, Janssen, Life Scan, Merck Sharp \& Dohme, Menarini, Novartis, Novo Nordisk, Roche, Sanofi, Servier and Takeda. SDP has received honoraria for advisory work and lectures from Astra Zeneca, Boheringer Ingelheim, Bristol Myers Squibb, Eli Lilly \& Co, Gl Dynamics Inc., GlaxoSmithKline, Hanmi Pharmaceuticals, Intarcia Therapeutics Inc, Janssen Pharmaceutics, Merck Sharpe \& Dohme, Novartis Pharmaceutical Co., Novo Nordisk, Roche Diagnostics Co., Sanofi Aventis, Takeda Pharmaceuticals, and Research support: Bristol Myers Squibb, Merck Sharpe \& Dohme, Novartis Pharmaceutical Co, Novo Nordisk.

Received: 21 June 2016 Accepted: 2 August 2016

Published online: 11 August 2016

\section{References}

1. Paneni F, Beckman JA, Creager MA, Cosentino F. Diabetes and vascular disease: pathophysiology, clinical consequences, and medical therapy: part I. Eur Heart J. 2013;34(31):2436-43.

2. Juutilainen A, Lehto S, Ronnemaa T, Pyorala K, Laakso M. Retinopathy predicts cardiovascular mortality in type 2 diabetic men and women. Diabetes Care. 2007;30(2):292-9.

3. Emerging Risk Factors C, Di Angelantonio E, Kaptoge S, Wormser D, Willeit P, Butterworth AS, Bansal N, O'Keeffe LM, Gao P, Wood AM, et al. Association of cardiometabolic multimorbidity with mortality. JAMA. 2015;314(1):52-60.

4. Emerging Risk Factors $\mathrm{C}$, Di Angelantonio E, Gao P, Khan H, Butterworth AS, Wormser D, Kaptoge S, Kondapally Seshasai SR, Thompson A, Sarwar $\mathrm{N}$, et al. Glycated hemoglobin measurement and prediction of cardiovascular disease. JAMA. 2014;311(12):1225-33.

5. Authors/Task Force M, Ryden L, Grant PJ, Anker SD, Berne C, Cosentino F, Danchin N, Deaton C, Escaned J, Hammes HP, et al. ESC guidelines on diabetes, pre-diabetes, and cardiovascular diseases developed in collaboration with the EASD: the Task Force on diabetes, pre-diabetes, and cardiovascular diseases of the European Society of Cardiology (ESC) and developed in collaboration with the European Association for the Study of Diabetes (EASD). Eur Heart J. 2013;34(39):3035-87.

6. Ceriello A. New insights on oxidative stress and diabetic complications may lead to a "causal" antioxidant therapy. Diabetes Care. 2003:26(5):1589-96.

7. Frier BM, Schernthaner G, Heller SR. Hypoglycemia and cardiovascular risks. Diabetes Care. 2011;34(Suppl 2):S132-7.

8. Pyorala K. Relationship of glucose tolerance and plasma insulin to the incidence of coronary heart disease: results from two population studies in Finland. Diabetes Care. 1979;2(2):131-41.

9. Ginsberg HN. Insulin resistance and cardiovascular disease. J Clin Invest. 2000;106(4):453-8

10. Wang P, Huang R, Lu S, Xia W, Sun H, Sun J, Cai R, Wang S. HbA1c below $7 \%$ as the goal of glucose control fails to maximize the cardiovascular benefits: a meta-analysis. Cardiovasc Diabetol. 2015;14:124. 
11. Paul SK, Klein K, Thorsted BL, Wolden ML, Khunti K. Delay in treatment intensification increases the risks of cardiovascular events in patients with type 2 diabetes. Cardiovasc Diabetol. 2015;14:100.

12. Gyberg $\vee$, De Bacquer D, De Backer G, Jennings C, Kotseva K, Mellbin L, Schnell O, Tuomilehto J, Wood D, Ryden L, et al. Patients with coronary artery disease and diabetes need improved management: a report from the EUROASPIRE IV survey: a registry from the EuroObservational Research Programme of the European Society of Cardiology. Cardiovasc Diabetol. 2015;14:133.

13. Boussageon R, Bejan-Angoulvant T, Saadatian-Elahi M, Lafont $S$, Bergeonneau C, Kassai B, Erpeldinger S, Wright JM, Gueyffier F, Cornu C. Effect of intensive glucose lowering treatment on all cause mortality, cardiovascular death, and microvascular events in type 2 diabetes: meta-analysis of randomised controlled trials. BMJ. 2011;343:d4169.

14. Valenzuela-Garcia LF, Matsuzawa Y, Sara JD, Kwon TG, Lennon RJ, Lerman LO, Ruiz-Salmeron RJ, Lerman A. Lack of correlation between the optimal glycaemic control and coronary micro vascular dysfunction in patients with diabetes mellitus: a cross sectional study. Cardiovasc Diabetol. 2015;14:106.

15. Gaede P, Vedel P, Larsen N, Jensen GV, Parving HH, Pedersen O. Multifactorial intervention and cardiovascular disease in patients with type 2 diabetes. N Eng J Med. 2003;348(5):383-93.

16. Triggle $\mathrm{CR}$, Ding $\mathrm{H}$. Cardiovascular impact of drugs used in the treatment of diabetes. Ther Adv Chronic Dis. 2014;5(6):245-68.

17. Ussher JR, Drucker DJ. Cardiovascular actions of incretin-based therapies. Circ Res. 2014;114(11):1788-803.

18. Touyz RM, Schiffrin EL. Peroxisome proliferator-activated receptors in vascular biology-molecular mechanisms and clinical implications. Vascul Pharmacol. 2006;45(1):19-28.

19. Kirpichnikov D, MCFarlane SI, Sowers JR. Metformin: an update. Ann Intern Med. 2002;137(1):25-33.

20. Fadini GP, Albiero M, Avogaro A. Direct effects of DPP-4 inhibition on the vasculature. Reconciling basic evidence with lack of clinical evidence. Vascul Pharmacol. 2015;73:1-3.

21. Ghosh RK, Bandyopadhyay D, Hajra A, Biswas M, Gupta A. Cardiovascular outcomes of sodium-glucose cotransporter 2 inhibitors: a comprehensive review of clinical and preclinical studies. Int J Cardiol. 2016;212:29-36.

22. U.S. Department of Health and Human Services FaDA, Center for Drug Evaluation and Research (CDER). Guidance for Industry. Diabetes mellitus - evaluating cardiovascular risk in new antidiabetic therapies to treat type 2 diabetes. 2008. http://wwwfdagov/downloads/drugs/ guidancecomplianceregulatoryinformation/guidances/ucm071627pdf. Accessed 20 July 2016.

23. Holman RR, Paul SK, Bethel MA, Matthews DR, Neil HA. 10-year followup of intensive glucose control in type 2 diabetes. N Eng J Med. 2008:359(15):1577-89.

24. Boussageon R, Gueyffier F, Cornu C. Metformin as firstline treatment for type 2 diabetes: are we sure? BMJ. 2016;352:h6748.

25. UK Prospective Diabetes Study (UKPDS) Group. Intensive blood-glucose control with sulphonylureas or insulin compared with conventional treat ment and risk of complications in patients with type 2 diabetes (UKPDS 33). Lancet. 1998;352(9131):837-53.

26. Group AC, Patel A, MacMahon S, Chalmers J, Neal B, Billot L, Woodward M, Marre M, Cooper M, Glasziou P et al. Intensive blood glucose control and vascular outcomes in patients with type 2 diabetes. N Eng J Med. 2008;358(24):2560-72.

27. Investigators OT, Gerstein HC, Bosch J, Dagenais GR, Diaz R, Jung H, Maggioni AP, Pogue J, Probstfield J, Ramachandran A, et al. Basal insulin and cardiovascular and other outcomes in dysglycemia. N Eng J Med. 2012;367(4):319-28.

28. Chiasson JL, Josse RG, Gomis R, Hanefeld M, Karasik A, Laakso M. Acarbose treatment and the risk of cardiovascular disease and hypertension in patients with impaired glucose tolerance: the STOP-NIDDM trial. JAMA 2003;290(4):486-94.

29. Van de Laar FA, Lucassen PL, Akkermans RP, Van de Lisdonk EH, Rutten GE, Van Weel C. Alpha-glucosidase inhibitors for type 2 diabetes mellitus. Cochrane Database Sys Rev. 2005;18(2):CD003639.

30. van de Laar FA, Lucassen PL. No evidence for a reduction of myocardial infarctions by acarbose. Eur Heart J. 2004; 25(13):1179; author reply 1179-1180
31. Hanefeld M, Cagatay M, Petrowitsch T, Neuser D, Petzinna D, Rupp M. Acarbose reduces the risk for myocardial infarction in type 2 diabetic patients: meta-analysis of seven long-term studies. Eur Heart J. 2004;25(1):10-6.

32. Dormandy JA, Charbonnel B, Eckland DJ, Erdmann E, Massi-Benedetti M, Moules IK, Skene AM, Tan MH, Lefebvre PJ, Murray GD, et al. Secondary prevention of macrovascular events in patients with type 2 diabetes in the PROactive Study (PROspective pioglitAzone clinical trial in macrovascular events): a randomised controlled trial. Lancet. 2005;366(9493):1279-89.

33. Nissen SE, Wolski K. Effect of rosiglitazone on the risk of myocardial infarction and death from cardiovascular causes. N Eng J Med. 2007;356(24):2457-71.

34. Singh S, Loke YK, Furberg CD. Long-term risk of cardiovascular events with rosiglitazone: a meta-analysis. JAMA. 2007;298(10):1189-95.

35. Mannucci E, Monami M, Marchionni N. Rosiglitazone and cardiovascular risk. N Eng J Med 2007; 357(9):938; author reply 939-940.

36. Menon V, Lincoff AM. Cardiovascular safety evaluation in the development of new drugs for diabetes mellitus. Circulation. 2014;129(25):2705-13.

37. Scirica BM, Bhatt DL, Braunwald E, Steg PG, Davidson J, Hirshberg B, Ohman P, Frederich R, Wiviott SD, Hoffman EB, et al. Saxagliptin and cardiovascular outcomes in patients with type 2 diabetes mellitus. N Eng J Med. 2013;369(14):1317-26.

38. White WB, Cannon CP, Heller SR, Nissen SE, Bergenstal RM, Bakris GL, Perez AT, Fleck PR, Mehta CR, Kupfer S, et al. Alogliptin after acute coronary syndrome in patients with type 2 diabetes. N Eng J Med. 2013;369(14):1327-35.

39. Green JB, Bethel MA, Armstrong PW, Buse JB, Engel SS, Garg J, Josse R, Kaufman KD, Koglin J, Korn S, et al. Effect of sitagliptin on cardiovascular outcomes in type 2 diabetes. N Eng J Med. 2015;373(3):232-42.

40. Pfeffer MA, Claggett B, Diaz R, Dickstein K, Gerstein HC, Kober LV, Lawson FC, Ping L, Wei $X$, Lewis EF, et al. Lixisenatide in patients with type 2 diabetes and acute coronary syndrome. N Eng J Med. 2015;373(23):2247-57.

41. Marso SP, Daniels GH, Brown-Frandsen K, Kristensen P, Mann JF, Nauck MA, Nissen SE, Pocock S, Poulter NR, Ravn LS, et al. Liraglutide and cardiovascular outcomes in type 2 diabetes. N Eng J Med. 2016;375(4):311-22.

42. Zinman B, Wanner C, Lachin JM, Fitchett D, Bluhmki E, Hantel S, Mattheus M, Devins T, Johansen OE, Woerle HJ, et al. Empagliflozin, cardiovascular outcomes, and mortality in type 2 diabetes. N Eng J Med. 2015;373(22):2117-28.

43. Fadini GP, Avogaro A, DegliEsposti L, Russo P, Saragoni S, Buda S, Rosano $G$, Pecorelli S, Pani L. Risk of hospitalization for heart failure in patients with type 2 diabetes newly treated with DPP-4 inhibitors or other oral glucose-lowering medications: a retrospective registry study on 127,555 patients from the nationwide OsMed Health-DB database. Eur Heart J. 2015;36(36):2454-62.

44. Li L, Li S, Deng K, Liu J, Vandvik PO, Zhao P, Zhang L, Shen J, Bala MM, Sohani ZN, et al. Dipeptidyl peptidase-4 inhibitors and risk of heart failure in type 2 diabetes: systematic review and meta-analysis of randomised and observational studies. BMJ. 2016;352:1610.

45. Sattar N, McLaren J, Kristensen SL, Preiss D, McMurray JJ. SGLT2 Inhibition and cardiovascular events: why did EMPA-REG Outcomes surprise and what were the likely mechanisms? Diabetologia. 2016;59(7):1573-4.

46. Marx N, McGuire DK. Sodium-glucose cotransporter-2 inhibition for the reduction of cardiovascular events in high-risk patients with diabetes mellitus. Eur Heart J. 2016. doi:10.1093/eurheartj/ehw110.

47. Wanner C, Inzucchi SE, Lachin JM, Fitchett D, von Eynatten M, Mattheus M, Johansen OE, Woerle HJ, Broedl UC, Zinman B. Empagliflozin and progression of kidney disease in type 2 diabetes. N Eng J Med. 2016;375(4):323-34.

48. Brenner BM, Cooper ME, de Zeeuw D, Keane WF, Mitch WE, Parving HH, Remuzzi G, Snapinn SM, Zhang Z, Shahinfar S, et al. Effects of losartan on renal and cardiovascular outcomes in patients with type 2 diabetes and nephropathy. N Eng J Med. 2001;345(12):861-9.

49. Fitchett D, Zinman B, Wanner C, Lachin JM, Hantel S, Salsali A, Johansen OE, Woerle HJ, Broedl UC, Inzucchi SE, et al. Heart failure outcomes with empagliflozin in patients with type 2 diabetes at high cardiovascular risk: results of the EMPA-REG Outcome(R) trial. Eur Heart J. 2016;37(19):1526-34. 
50. Ferrannini E, Mark M, Mayoux E. CV protection in the EMPA-REG Outcome Trial: a "Thrifty Substrate" hypothesis. Diabetes Care. 2016;39(7):1 108-14.

51. Schneider CA, Ferrannini E, Defronzo R, Schernthaner G, Yates J, Erdmann E. Effect of pioglitazone on cardiovascular outcome in diabetes and chronic kidney disease. J Am Soc Nephrol. 2008;19(1):182-7.

52. D'Alessio D, Haring HU, Charbonnel B, de Pablos-Velasco P, Candelas C, Dain MP, Vincent M, Pilorget V, Yki-Jarvinen H. Comparison of insulin glargine and liraglutide added to oral agents in patients with poorly controlled type 2 diabetes. Diabetes Obes Metab. 2015;17(2):170-8.

53. Li WX, Gou JF, Tian JH, Yan X, Yang L. Glucagon-like peptide-1 receptor agonists versus insulin glargine for type 2 diabetes mellitus: a systematic review and meta-analysis of randomized controlled trials. Curr Ther Res Clin Exp. 2010;71(4):211-38.

54. Gitt AK, Bramlage P, Schneider S, Tschope D. A real world comparison of sulfonylurea and insulin vs. incretin-based treatments in patients not controlled on prior metformin monotherapy. Cardiovasc Diabetol. 2015;14:13.

55. Ritsinger V, Malmberg K, Martensson A, Ryden L, Wedel H, Norhammar A. Intensified insulin-based glycaemic control after myocardial infarction: mortality during 20 year follow-up of the randomised diabetes mellitus insulin glucose infusion in acute myocardial infarction (DIGAMI 1) trial. Lancet Diabetes Endocrinol. 2014:2(8):627-33.

56. Malmberg K, Ryden L, Hamsten A, Herlitz J, Waldenstrom A, Wedel H. Effects of insulin treatment on cause-specific one-year mortality and morbidity in diabetic patients with acute myocardial infarction. DIGAMI study group. diabetes insulin-glucose in acute myocardial infarction. Eur Heart J. 1996;17(9):1337-44.

57. Malmberg K, Ryden L, Wedel H, Birkeland K, Bootsma A, Dickstein K, Efendic S, Fisher M, Hamsten A, Herlitz J, et al. Intense metabolic control by means of insulin in patients with diabetes mellitus and acute myocardial infarction (DIGAMI 2): effects on mortality and morbidity. Eur Heart J. 2005;26(7):650-61.

58. Fadini GP, de Kreutzenberg SV, Gjini R, Avogaro A. The metabolic syndrome influences the response to incretin-based therapies. Acta Diabetol. 2011:48(3):219-25.
59. DeFronzo RA, Abdul-Ghani M. Type 2 diabetes can be prevented with early pharmacological intervention. Diabetes Care. 2011;34(Suppl 2):S202-9.

60. Nissen SE, Nicholls SJ, Wolski K, Nesto R, Kupfer S, Perez A, Jure H, De Larochelliere R, Staniloae CS, Mavromatis K, et al. Comparison of pioglitazone vs glimepiride on progression of coronary atherosclerosis in patients with type 2 diabetes: the PERISCOPE randomized controlled trial. JAMA. 2008;299(13):1561-73.

61. Paul SK, Klein K, Maggs D, Best JH. The association of the treatment with glucagon-like peptide-1 receptor agonist exenatide or insulin with cardiovascular outcomes in patients with type 2 diabetes: a retrospective observational study. Cardiovasc Diabetol. 2015;14:10.

62. Wilke T, Mueller S, Groth A, Fuchs A, Seitz L, Kienhofer J, Maywald U, Lundershausen R, Wehling M. Treatment-dependent and treatment-independent risk factors associated with the risk of diabetes-related events: a retrospective analysis based on 229,042 patients with type 2 diabetes mellitus. Cardiovasc Diabetol. 2015;14:14.

63. Jiao F, Fung CS, Wan YF, McGhee SM, Wong CK, Dai D, Kwok R, Lam $\mathrm{CL}$. Long-term effects of the multidisciplinary risk assessment and management program for patients with diabetes mellitus (RAMP-DM): a population-based cohort study. Cardiovasc Diabetol. 2015;14:105.

64. Wing RR, Bolin P, Brancati FL, Bray GA, Clark JM, Coday M, Crow RS, Curtis $J M$, Egan CM, Espeland MA, et al. Cardiovascular effects of intensive lifestyle intervention in type 2 diabetes. N Eng J Med. 2013;369(2):145-54

65. Spiegel R. Reasons to recommend lifestyle changes in type 2 diabetes mellitus and obesity. Nat Rev Cardiol. 2013;10(11):678.

66. Zhou X, Yu J, Li L, Gloy VL, Nordmann A, Tiboni M, Li Y, Sun X. Effects of bariatric surgery on mortality, cardiovascular events, and cancer outcomes in obese patients: systematic review and meta-analysis. Obes Surg. 2016. doi:10.1007/s11695-016-2144-x.

67. Kwok CS, Pradhan A, Khan MA, Anderson SG, Keavney BD, Myint PK, Mamas MA, Loke YK. Bariatric surgery and its impact on cardiovascular disease and mortality: a systematic review and meta-analysis. Int J Cardiol. 2014;173(1):20-8.

\section{Submit your next manuscript to BioMed Central and we will help you at every step:}

- We accept pre-submission inquiries

- Our selector tool helps you to find the most relevant journal

- We provide round the clock customer support

- Convenient online submission

- Thorough peer review

- Inclusion in PubMed and all major indexing services

- Maximum visibility for your research

Submit your manuscript at www.biomedcentral.com/submit
O Biomed Central 